\title{
SALURAN PEMASARAN BUAH SALAK DI DESA BAWOLEU KECAMATAN TAGULANDANG UTARA KABUPATEN KEPULAUAN SIAU TAGULANDANG BIARO
}

\author{
Timotius Fernel Makinggung \\ Olly Esry Haryani Laoh \\ Martha Mareyke Sendow
}

\begin{tabular}{ll}
\hline Naskah diterima melalui Website Jurnal Ilmiah agrisosioekonomi@unsrat.ac.id & : Senin, 23 Desember 2019 \\
Disetujui diterbitkan & : Selasa, 31 Desember 2019 \\
\hline
\end{tabular}

\begin{abstract}
This study aims to determine the marketing of salak fruit, analyze profits and marketing margins of zalacca, and analyze the farmer's share in each marketing channel of zalacca in Bawoleu Village. This research was carried out in Bawoleu Village, North Tagulandang District, Siau Tagulandang Biaro Regency. The sample selection is done purposevely and snowball method. Data collected are primary and secondary data. Primary data collection was carried out by direct interviews with 16 salak farmers and related marketing institutions. The data collected are the characteristics of respondents, the characteristics of salak fruit farming, prices at the level of farmers, traders, and consumers, as well as marketing institutions in marketing salak fruit. Secondary data obtained from the Internet through Google searching. The results showed that the marketing channels formed in the marketing of salak fruit in Bawoleu Village were 3 types of marketing channels, namely marketing channel I, which had a total cost of Rp. $575 / \mathrm{Kg}$, Marketing channel II the total cost of Rp 575 / kg, profit of Rp 15,675 / Kg and marketing margin of Rp 16,250 / Kg. Marketing channel III costs a total of Rp. 875 / Kg, Profits Rp. 375 / Kg, marketing margin Rp. 1,250/ Kg. The portion received by farmers (farmer share) in marketing channel I is 100\%, marketing channel II is $18.75 \%$, marketing channel III is $75 \%$. ${ }^{*}$ prm*
\end{abstract}

Keywords: salak, marketing channels, profits, marketing margins, farmer's share

\begin{abstract}
ABSTRAK
Penelitian ini bertujuan untuk mengetahui saluran pemasaran buah salak, menganalisis besar biaya, keuntungan dan margin pemasaran buah salak, serta menganalisis farmer's share disetiap saluran pemasaran buah salak di Desa Bawoleu. Penelitian ini dilakukan di Desa Bawoleu Kecamatan Tagulandang Utara Kabupaten Kepulauan Siau Tagulandang Biaro. Data yang dikumpulkan adalah data primer dan sekunder. Data sekunder diperoleh dari Internet melalui google searching. Pemilihan sampel dilakukan dengan cara secara sengaja dan metode snowball. Pengumpulan data primer dilakukan dengan cara wawancara langsung dengan 16 petani salak dan lembaga pemasaran terkait. Data yang dikumpulkan adalah karakteristik responden, karakteristik usahatani buah salak, harga di tingkat petani, pedagang, dan konsumen, serta lembaga pemasaran dalam memasarkan buah salak. Hasil penelitian menunjukkan bahwa saluran pemasaran yang terbentuk pada pemasaran buah salak di Desa Bawoleu ada 3 bentuk saluran pemasaran yaitu Saluran pemasaran I total biaya Rp. $575 / \mathrm{Kg}$, Saluran pemasaran II total biaya Rp 575/kg, keuntungan Rp 15.675/Kg dan margin pemasaran Rp 16.250/Kg. Saluran pemasaran III total biaya Rp 875/Kg, Keuntungan Rp 375/Kg, margin pemasaran Rp 1.250/Kg. Bagian yang diterima petani (farmer's share) pada saluran pemasaran I sebesar $100 \%$, saluran pemasaran II sebesar 18,75\%, saluran pemasaran III sebesar $75 \%{ }^{*}{ }^{\text {eprm* }}$
\end{abstract}

Kata kunci: salak, saluran pemasaran, keuntungan, margin pemasaran, bagian yang diterima petani

Agrisosioekonomi:

Jurnal Transdisiplin Pertanian (Budidaya Tanaman, Perkebunan, Kehutanan, Peternakan, Perikanan), Sosial dan Ekonomi 


\section{PENDAHULUAN}

\section{Latar Belakang}

Indonesia sampai saat ini masih tergolong negara yang sedang berkembang. Selain itu, Indonesia juga merupakan negara agraris dipedesaan dengan mata pencaharian di sektor pertanian. Dalam rangka pembangunan perekonomian di Indonesia, maka semua potensi digunakan dan dimanfaatkan untuk lebih meningkatkan pembangunan itu sendiri, khususnya disektor pertanian dapat memperluas lapangan pekerjaan, menigkatkan pendidikan petani, peternak dan pekebun serta mendorong pemerataan pembangunan daerah dengan tetap memperhatikan kelestarian sumber daya alamnya (Daniel, 2002).

Pertanian mendapat prioritas utama karena sektor ini merupakan sektor yang dominan dalam perekonomian nasional. Pembangunan pertanian saat ini diharapkan menjadi sektor andalan yang dapat dengan cepat menghasilkan dan meningkatkan pendapatan masyarakat melalui penyediaan lapangan kerja juga dalam proses produksi sampai pada pemasaran komoditi pertanian. (Sumodiningrat, 2000).

Peningkatan pendapatan petani harus ditunjang dengan harga pasar dan sistem pemasaran yang baik agar arus distribusi barang dari produsen ke konsumen berjalan dengan baik. Peningkatan produksi tanpa adanya pemasaran akan mengurangi pendapatan petani dan mempengaruhi petani dalam produksi (Mosher, 1981).

Menurut Soekartawi (2005), untuk memperoleh nilai jual yang baik, maka mekanisme pemasaran harus berjalan dengan baik dengan tujuan agar semua pihak lain yang terlibat diuntungkan. Bagi konsumen tingkat harga yang tinggi merupakan beban. Bagi petani produsen perolehan keuntungan dapat diterima rendah atau berkurang karena rendahnya tingkat harga yang diterima. Pendapatan petani sangat dipengaruhi oleh pemasaran hasil produksinya dan harga yang berlaku, dimana pemasaran yang kurang efisien adalah kecilnya bagian yang diterima petani dari harga yang dibayar konsumen akhir.
Komoditi hortikultura merupakan komoditi yang mempunyai kedudukan yang penting dalam masyarakat maupun perekonomian negara. Pengembangan produksi hortikultura sebagai sumber gizi ditingkatkan untuk pertumbuhan manusia di Indonesia yang sehat dan berkembang tinggi dalam memikul tugas pembangunan yang semakin berat. (Sudiyono, 2004).

Kecamatan Tagulandang Utara merupakan salah satu wilayah di Kabupaten Kepulauan Siau, Tagulandang, Biaro khususnya di Desa Bawoleu sebagai salah satu pusat perkebunan salak, sehingga tanaman ini merupakan salah satu sumber pendapatan petani setiap tahunnya disamping pendapatan petani dari tanaman lainnya sebagai produk yang diusahakan oleh petani. Produksi dan pemasaran harga buah salak sangat berperan penting dalam meningkatkan kesejahteraan petani di Desa Bawoleu.

\section{Rumusan Masalah}

Berdasarkan uraian diatas dirumuskan permasalahan yang menjadi fokus penelitian yaitu:

1. Bagaimana saluran pemasaran buah salak di Desa Bawoleu?

2. Berapa besar biaya, keuntungan dan margin pemasaran disetiap saluran pemasaran buah salak di Desa Bawoleu?

3. Bagaimana Farmer's share disetiap saluran pemasaran buah salak di Desa Bawoleu?

\section{Tujuan Penelitian}

1. Mengetahui saluran pemasaran buah salak di Desa Bawoleu.

2. Menganalisis besar biaya, keuntungan dan margin pemasaran buah salak di Desa Bawoleu.

3. Menganalisis farmer's share disetiap saluran pemasaran buah salak di Desa Bawoleu.

\section{Manfaat Penelitian}

Penelitian ini diharapkan dapat memberikan informasi kepada petani buah salak di Desa Bawoleu Kecamatan Tagulandang Utara Kabupaten Siau Tagulandang Biaro mengenai saluran pemasaran komoditi buah salak. 


\section{METODE PENELITIAN}

\section{Lokasi dan Waktu Penelitian}

Penelitian dilaksanakan selama 3 bulan yaitu mulai dari bulan Juli sampai dengan bulan September 2019. Lokasi penelitian di Desa Bawoleu Kecamatan Tagulandang Utara Kabupaten Kepulauan Siau Tagulandang Biaro.

\section{Metode Pengambilan Data}

Metode yang digunakan dalam penelitian ini adalah wawancara langsung. Data yang dikumpulkan merupakan data primer yang diperoleh langsung dilapangan dengan mengajukan pertanyaan kepada responden menggunakan kuesioner. Responden yang diambil dalam penelitian ini yaitu petani salak yang ada di Desa Bawoleu Kecamatan Tagulandang Utara Kabupaten Kepulauan Siau Tagulandang Biaro dan lembaga pemasaran terkait.

Jumlah responden sebanyak 16 orang meliputi petani salak dan lembaga pemasaran yang terkait.

\section{Metode Pengambilan Sampel}

Metode Pengambilan sampel dilakukan dengan cara Purposive Sampling (secara sengaja) dan metode snowball Sampling, dimana sampel diperoleh berdasarkan informasi dari responden pertama yaitu petani salak, kemudian di telusuri hingga ke konsumen akhir.

\section{Konsep Pengukuran Variabel}

1. Karaktaeristik Responden:
a. Umur
b. Tingkat Pendidikan
c. Jumlah Tanggungan
d. Lama Berusahatani

2. Karakteristik usahatani buah salak yang meliputi:

a. Luas lahan (Ha)

b. Jumlah produksi salak dalam satu kali panen $(\mathrm{Kg} / \mathrm{Ha})$

3. Harga di tingkat petani yaitu penerimaan harga petani salak dari lembaga pemasaran $(\mathrm{Rp} / \mathrm{Kg})$.

4. Harga di tingkat pedagang pengumpul yaitu harga yang diterima dari pedagang pengumpul dari hasil penjualan kepada konsumen $(\mathrm{Rp} / \mathrm{Kg})$.

5. Harga di tingkat konsumen yaitu harga yang yang diterima konsumen dari penjualan di tingkat pengecer $(\mathrm{Rp} / \mathrm{Kg})$.

6. Lembaga pemasaran dalam memasarkan buah salak.

a. Biaya pengepakan / pengemasan $(\mathrm{Rp} / \mathrm{Kg})$

b. Biaya pengangkutan/transportasi $(\mathrm{Rp} / \mathrm{Kg})$

c. Biaya tenaga kerja $(\mathrm{Rp} / \mathrm{Kg})$

d. Biaya retribusi $(\mathrm{Rp} / \mathrm{Kg})$

\section{Metode Analisis Data}

Metode analisis data yang digunakan dalam penelitian adalah:

1. Saluran pemasaran buah salak di Desa Bawoleu Kecamatan Tagulandang Utara yang diketahui dengan mengikuti aliran pemasaran buah salak dari petani produsen sampai ke konsumen akhir. Data dikumpulkan dan dianalisis secara deskrptif dan disajikan dalam bentuk tabel.

2. Untuk mengetahui margin pemasaran dan biaya pemasaran di tingkat lembaga pemasaran pada saluran pemasaran digunakan analisis kuantitatif yaitu dengan menghitung besar biaya, keuntungan dan margin pemasaran, dengan rumus:

a. Margin Pemasaran menurut Pearce dan Robinson (2011).

$$
\begin{aligned}
& \text { Dimana: } \\
& M P=P r-P f \\
& \text { MP : Margin Pemasaran } \\
& \text { Pr : Harga di tingkat consume } \\
& (\mathrm{Rp} / \mathrm{Kg}) \\
& \text { Pf : Harga di tingkat } \\
& \text { produsen/petani }(\mathrm{Rp} / \mathrm{Kg})
\end{aligned}
$$

b. Biaya Pemasaran menurut Rahmi dan Hastuti (2007).

$$
\begin{array}{cl}
\boldsymbol{B p}=\boldsymbol{B p} \mathbf{1} & +\boldsymbol{B} \boldsymbol{p} \mathbf{2}+\boldsymbol{B p} \mathbf{3}+\cdots+\boldsymbol{B p} \boldsymbol{n} \\
\text { Dimana: } & \\
\mathrm{Bp} & =\text { Biaya Pemasaran }(\mathrm{Rp} / \mathrm{Kg}) \\
\mathrm{i} & =1,2,3 \ldots \mathrm{n} \\
\mathrm{n} & =
\end{array}
$$

Bp1,2,3, $\mathrm{n}=$ Biaya Pemasaran tiap

Lembaga Pemasaran $(\mathrm{Rp} / \mathrm{Kg})$

c. Keuntungan Pemasaran

$$
\boldsymbol{P}=\boldsymbol{M}-\boldsymbol{C}
$$

Dimana:

$\mathrm{P}=$ Keuntungan Margin $(\mathrm{Rp} / \mathrm{Kg})$

$\mathrm{M}=$ Harga ditingkat Pedagang $(\mathrm{Rp} / \mathrm{Kg})$

$\mathrm{C}=$ Biaya Pemasaran $(\mathrm{Rp} / \mathrm{Kg})$

d. Farmer's share

Dihitung dengan menggunakan rumus:

Sarma (1995) dalam Kaparang (2015)

$$
F s=\frac{P f}{P r} \times 100 \%
$$

Dimana:

Fs = Bagian yang diterima petani

$\mathrm{Pf}=$ Harga di tingkat petani $(\mathrm{Rp} / \mathrm{Kg})$

$\mathrm{Pr}=$ Harga di tingkat konsumen $(\mathrm{Rp} / \mathrm{Kg})$ 


\section{HASIL DAN PEMBAHASAN}

\section{Deskripsi Lokasi Penelitian}

\section{Keadaan Geografis Lokasi Penelitian}

Kecamatan Tagulandang Utara merupakan salah satu wilayah di Kabupaten Kepulauan Siau Tagulandang Biaro. Desa Bawoleu merupakan salah satu desa dari 6 desa yang ada di Kecamatan Tagulandang Utara dan merupakan ibukota kecamatan yang terletak antara 2021'40'LU20'22'30'LU dan 125025'25'25'BT1250'25'50'BT dengan Luas wilayah sebesar 1752 $\mathrm{Ha}$.

\section{Karakteristik Responden Petani}

\section{Umur Petani}

Seorang yang bekerja pada sektor pertanian pasti mengandalkan kemampuan fisik, sehingga fisik yang kuat dan sehat pasti berproduktivitas lebih besar di bandingkan dengan yang sudah tua. Makin tinggi umur seseorang maka akan semakin berkurang kemampuan seseorang untuk bekerja.

\begin{tabular}{lccc}
\multicolumn{4}{c}{ Tabel 1. Jumlah Responden Petani Tingkat Umur. } \\
\hline No. & $\begin{array}{c}\text { Umur } \\
\text { (Tahun) }\end{array}$ & $\begin{array}{c}\text { Jumlah Responden } \\
\text { (Orang) }\end{array}$ & Persentase (\%) \\
\hline 1. & $40-50$ & 5 & 50 \\
2. & $51-60$ & 3 & 30 \\
3. & $61-70$ & 2 & 20 \\
\hline & Jumlah & $\mathbf{1 0}$ & $\mathbf{1 0 0}$ \\
\hline
\end{tabular}

Sumber: Data Primer Yang Diolah, 2019

Tabel 1 menunjukkan bahwa kisaran umur responden petani buah salak di Desa Bawoleu adalah 40-70 tahun. Sebagian besar responden petani berada pada kelompok umur 40-50 tahun. Jumlah petani pada kelompok ini sebanyak 5 orang petani atau $50 \%$. Berdasarkan hasil penelitian dapat di katakan bahwa petani yang berada di Desa Bawoleu berada pada umur produktif.

\section{Tingkat Pendidikan Petani}

Pendidikan merupakan faktor yang sangat penting untuk meningkatkan sumberdaya manusia, karena pendidikan dapat meningkatkan intelektual seseorang sehingga akan lebih mudah menerima informasi untuk mengimplementasikan ke dalam usahataninya.

\begin{tabular}{cccc} 
Tabel 2. Jumlah Petani Menurut Tingkat Pendidikan \\
\hline No. & $\begin{array}{c}\text { Tingkat } \\
\text { Pendidikan }\end{array}$ & $\begin{array}{c}\text { Jumlah Responden } \\
\text { (Orang) }\end{array}$ & $\begin{array}{c}\text { Persentase } \\
(\boldsymbol{\%})\end{array}$ \\
\hline 1. & SD & 3 & 30 \\
2. & SMP & 3 & 30 \\
3. & SMA & 4 & 40 \\
4. & S1 & - & - \\
\hline & Jumlah & $\mathbf{1 0}$ & $\mathbf{1 0 0}$ \\
\hline
\end{tabular}

Tabel 2 menunjukkan bahwa tingkat pendidikan respoden petani termasuk dalam kategori cukup tinggi. Hal ini terlihat pada tingkat pendidikan SMA memiliki nilai persentase terbesar yaitu $40 \%$ dari jumlah responde petani 4 orang.

\section{Jumlah Tanggungan Petani}

Tingkat kesejaterran keluarga di pengaruhi oleh berbagai faktor salah satunya yaitu jumlah tanggungan keluarga. Jumlah tanggungan mempengaruhi pada pengeluaran keluarga, semakin banyak jumlah tanggungan semakin besar pengeluaran sehingga menyebabkan pendapatan petani lebih sedikit yang pada akhirnya menurunkan kesejahteraan keluarga petani. Akan tetapi, banyaknya jumlah tanggungan dalam keluarga juga menbantu dalam hal penyediaan tenaga kerja karena akan mengurangi permintaan tenaga kerja dari luar keluarga, dengan demikian mengurangi biaya tenaga kerja.

\begin{tabular}{lccc} 
Tabel & $\begin{array}{c}\text { 3. } \\
\text { Jumlah } \\
\text { Tanggungan Keluarga }\end{array}$ & $\begin{array}{c}\text { Responden } \\
\text { Nangiani }\end{array}$ & menurut \\
\hline No. & $\begin{array}{c}\text { Jumlah } \\
\text { Tanggungan } \\
\text { (Orang) }\end{array}$ & $\begin{array}{c}\text { Jumlah } \\
\text { Responden } \\
\text { (Orang) }\end{array}$ & $\begin{array}{c}\text { Persentase } \\
(\%)\end{array}$ \\
\hline 1. & $0-1$ & 2 & 20 \\
2. & 2 & 6 & 60 \\
3. & 3 & 2 & 20 \\
\hline & Jumlah & $\mathbf{1 0}$ & $\mathbf{1 0 0}$ \\
\hline
\end{tabular}

Sumber: Data Primer yang Diolah, 2019.

Tabel 3 menunjukkan bahwa sebagian responden petani buah salak di Desa Bawoleu mempunyai jumlah tangungan keluarga 2 orang. Jumlah responden petani yang memiliki tanggungan 2 yaitu 6 orang atua $60 \%$ dari total responden. Dari uraian tersebut dapa disimpulkan bahwa kesadaran petani akan keluarga berencana yang di terapkan pemerintah cukup tinggi.

\section{Pengalaman Bertani}

Keberhasilan usahtani tidak terlepas dari pengalaman petani dalam berusaha. Pengalaman usahatani juga berpengaruh terhadap pengetahuan dan ketrampilan petani dalam mengalokasikan faktor produksi dalam penerapan teknologi baru maupun pemasarannya. 
Tabel 4. Jumlah dan Presentase Pengalaman Usahatani Buah Salak Responden Petani

\begin{tabular}{|c|c|c|c|}
\hline No. & $\begin{array}{c}\text { Lama Usahatani } \\
\text { Buah salak } \\
\text { (Tahun) }\end{array}$ & $\begin{array}{c}\text { Jumlah } \\
\text { Responden } \\
\text { (Orang) }\end{array}$ & $\begin{array}{c}\text { Persentase } \\
(\%)\end{array}$ \\
\hline 1. & $15-20$ & 3 & 30 \\
\hline 2. & $21-25$ & 3 & 30 \\
\hline \multirow[t]{2}{*}{3.} & $26-30$ & 4 & 40 \\
\hline & Jumlah & 10 & 100 \\
\hline
\end{tabular}

Sumber: Data Primer yang Diolah, 2019.

Tabel 4 dapat lihat pengalaman usahatani responden petani buah salak berkisaran antara 1530 tahun. Sebagian besar responden petani menjalankan usahtani buah salak berada pada 2630 tahun sebanyak 4 orang atau $40 \%$. Penduduk di Desa Bawoleu Kecamatan Tagulandang Utara pada umumnya telah lama menjalankan usahatani buah salak ini bahkan sudah sebagai mata pencaharian.

\section{Karakteristik Responden Lembaga Pemasaran Buah Salak}

\section{Tingkat Umur}

Faktor umur dan kondisi fisik pedagang berpengaruh pada aktivitas pada pemasaran buah salak yang dijalankannya karena pada umumnya pedagang terlibat secara langsung baik selama proses pembelian maupun penjualan buah salak.

\begin{tabular}{|c|c|c|c|c|c|}
\hline No & $\begin{array}{c}\text { Umur } \\
\text { (Tahun) }\end{array}$ & $\begin{array}{l}\text { Pedagang } \\
\text { Pengumpul } \\
\text { (Orang) }\end{array}$ & $\begin{array}{c}\text { Persentase } \\
(\%)\end{array}$ & $\begin{array}{c}\text { Pedagang } \\
\text { Pengecer } \\
\text { (Orang) }\end{array}$ & $\begin{array}{c}\text { Persentase } \\
(\%)\end{array}$ \\
\hline 1. & $30-40$ & 1 & 50 & 2 & 50 \\
\hline 2. & $41-50$ & - & - & 1 & 25 \\
\hline 3. & $51-60$ & 1 & 50 & 1 & 25 \\
\hline \multicolumn{2}{|c|}{ Jumlah } & 2 & 100 & 4 & 100 \\
\hline
\end{tabular}

Sumber: Data Primer yang Diolah, 2019.

Tabel 5 menunjukkan bahwa kisaran umur pedagang perantara pemasaran buah salak di Desa Bawoleu adalah 30-60. Sebagian besar responden pedagang perantara berada pada kelompok umur 3040 tahun. Jumlah responden pedagang pengumpul sebanyak 1 responden atau 50 persen, pedagang pengecer sebanyak 2 responden atau 50 persen.

\section{Tingkat Pendidikan}

Faktor pendidikan mempengaruhi pengambilan keputusan yang dilakukan oleh pedagang dalam memasarkan buah salak. Pendidikan yang di tempu dapat mempermudah pedaganag dalam menjalankan usahanya terutama dalam perhitungan pendapatan serta penyerapan teknologi yang baru yang dapat menunjang usaha.
Komposisi tingkat pendidikan responden dalam penelitian ini dapa dilihat pada Tabel 6 .

\begin{tabular}{lccccc}
\multicolumn{6}{c}{ Tabel 6. Responden Pedagang Menurut Tingkat Pendidikan. } \\
\hline No & $\begin{array}{c}\text { Tingkat } \\
\text { Pendidikan }\end{array}$ & $\begin{array}{c}\text { Pedagang } \\
\text { Pengumpul } \\
\text { (Orang) }\end{array}$ & $\begin{array}{c}\text { Persentase } \\
(\boldsymbol{\%})\end{array}$ & $\begin{array}{c}\text { Pedagang } \\
\text { Pengecer } \\
\text { (Orang) }\end{array}$ & $\begin{array}{c}\text { Persentase } \\
(\%)\end{array}$ \\
\hline 1. & SD & - & - & 1 & 25 \\
2. & SMP & 1 & 50 & 2 & 50 \\
3. & SMA & 1 & 50 & 1 & 25 \\
& S1 & - & - & - & - \\
\hline \multicolumn{7}{r}{ Jumlah } & $\mathbf{2}$ & $\mathbf{1 0 0}$ & $\mathbf{4}$ & $\mathbf{1 0 0}$ \\
\hline \multicolumn{5}{l}{ Sumber: Data Primer yang Diolah, 2019. }
\end{tabular}

Tabel 6 menunjukkan bahwa pendidikan pedagang perantara di Desa Bawoleu termasuk dalam kategori yang bervariasi. Hal ini terlihat pada tingkat pendidikan SMP 1 responden pedagang pengumpul 50 persen, SMP 2 responden pedagang pengecer 50 persen dan di tingkat SMA 1 responden pedagang pengumpul 50 persen. Dengan pendidikan pedagang demikian diharapkan dapat mempengaruhi daya serap sehingga dapat mengikuti informasi pasar mengenai harga buah salak dengan baik.

\section{Pengalaman Berdagang}

Pengalaman yang di miliki pedagang dapat terlihat dari berapa lama mereka menjalankan usah nya dalam hal ini memasarkan buah salak,

Pengalaman dan lamanya menekuni profesi sebagai pedagang baik, pedagang pengumpul pedagang pengecer yang ada di Desa Bawoleu yaitu pengalaman berusaha dari pedagang pengumpul 2 responden 25 tahun, pedagang pengecer yaitu 1 responden 20 tahun, 2 responden 15 tahun, dan 1 responden 30 tahun.

\section{Usahatani Buah Salak}

\section{Luas Lahan dan Jumlah Produksi}

Lahan merupakan faktor produksi yang memegang peranan penting bagi usahatani, karena lahan sangat dibutukan sebagai wadah untuk menanam komoditi atau tanaman yang ingin diusahakan oleh petani. Jumlah produksi merupakan faktor penentu besarnya pendapatan yang akan diterima petani. Luas lahan dan jumlah produksi dapat dilihat pada Tabel 7. 
Tabel 7. Luas Lahan dan Jumlah Produksi Buah Salak di

\begin{tabular}{cccc}
\multicolumn{2}{c}{ Desah Bawoleu } & \multicolumn{2}{c}{ Produksi Buah Salak } \\
Responden & Luas Lahan & Kg & Karung \\
\hline (Orang) & (ha) & 80 & 2 \\
1 & 0,03 & 120 & 3 \\
2 & 0,48 & 800 & 20 \\
3 & 1,00 & 80 & 2 \\
4 & 0,04 & 120 & 3 \\
5 & 0,15 & 200 & 5 \\
6 & 1,00 & 600 & 15 \\
7 & 1,5 & 200 & 5 \\
8 & 0,08 & 80 & 2 \\
9 & 0,04 & 120 & 3 \\
10 & 0,14 & $\mathbf{2 4 0 0}$ & $\mathbf{6 0}$ \\
\hline Jumlah & $\mathbf{4 , 4 6}$ &
\end{tabular}

Tabel 7 menunjukkan bahwa produksi buah salak adalah $2400 \mathrm{Kg}$ setara dengan 60 karung. Resiko yang dihadapi petani dalam pemasaran buah salak diantaranya buah salak yang rusak dalam proses pendistribusian dan buah salak yang tidak habis terjual. Secara umum menurut responden persentase resiko kerusakan yang dihadapi petani cukup kecil yaitu dibawah $10 \%$.

\section{Lembaga Pemasaran Buah Salak di Desa Bawoleu}

Kegiatan pemasaran buah salak dari produsen ke konsumen memerlukan pedagang perantara atau biasa di sebut lembaga pemasara. Berdasarkan penelitian di dapati bahwa petani buah salak di Desa Bawoleu menggunakan jasa lembaga pemasaran untuk menyalurkan hasil produksi buah salak hingga sampai ketangan konsumen. Maising-masing lembaga pemasaran mempunyai peranan penting dalam memasarkan buah salak.

\section{Pedagang Pengumpul}

Pedagang pengumpul merupakan pedagang perantara yang mengumpul buah salak kemudian akan di salurkan ke pedagang besar yang berada di Manado.

\section{Pedagang Pengecer}

Pedagang pengecer merupakan pedagang perantara terakhir yang di temukan pada saluran pemasaran. Hasil penelitian menunjukkan bahwa ada 4 pedagang pengecer di Desa Bawoleu, dimana ke empat pedagang pengecer ini menjual buah salak langsung kepada konsumen akhir, Di pasar buhias dan pelabuhan kapal laut tagulandang.

3. Konsumen

Konsumen merupakan orang yang membeli buah salak dari pedagang pengecer maupun lembaga pemasaran yang terlibat untuk di konsumsi.

\section{Saluran Pemasaran Buah Salak di Desa Bawoleu \\ Kecamatan Tagulandang Utara}

Saluran pemasaran merupakan serangkaian lembaga yang melakukan semua fungsi untuk menyalurkan barang dari produsen ke konsumen. saluran pemasaran buah salak di Desa Bawoleu dapat diketahui dengan cara mengikuti arus pemasaran buah salak mulai dari petani produsen sampai kepada konsumen. Berdasarkan hasil penelitian yang dilakukan, menunjukkan ada 3 saluran pemasaran buah salak di Desa Bawoleu Kecamatan Tagulandang Utara yaitu:

1. Saluran pemasaran I

Petani $\longrightarrow$ Konsumen

Pada salura pemasaran I, petani menjual buah salak langsung ke konsumen akhir di pasar buhias dan pelabuhan kapal laut Tagulandang.

2. Saluran pemasaran II

Petani $\longrightarrow$ Pengecer $\longrightarrow$ Konsumen

Pada saluran pemasaran II petani menjual buah salak ke pengecer, dan pengecer yang memasarkan buah salak ke konsumen di pasar Buhias dan Pelabuhan laut tagulandang.

3. Saluran pemasaran III

Petani $\longrightarrow$ Pengecer $\longrightarrow$ Pengumpul Pedagang besar di manado

Pada saluran pemasaran III memiliki perantara yang disebut pedagan pengumpul yang mengumpulkan buah salak dari petani dan pengecer di Desa Bawoleu kemudian dibawa ke pedagang besar di Manado.

\section{Margin Pemasaran dan Farmer's share}

Berdasarkan hasil penelitian yang diketahui ada 3 jenis saluran pemasaran buah salak yang ada di Desa Bawoleu Kecamatan Tagulandang Utara. Dengan adanya jumlah lembaga pemasaran yang terlibat pada setiap saluran pemasaran menyebabkan margin pemasaran yang berbeda.

\section{Margin Pemasaran dan Farmer's Share Pada Saluran Pemasaran I}

Rata-rata biaya, keuntungan, margin pemasaran dan farmer's share pada saluran pemasaran I dapa dilihat pada Tabel 8. 
Tabel 8. Komponen Biaya, Keuntungan, Margin Pemasaran dan Farmer's Share Pada Saluran Pemasaran I

\begin{tabular}{lcc}
\hline \multicolumn{1}{c}{ Komoponen Biaya } & $\begin{array}{c}\text { Harga } \\
(\mathbf{R p} / \mathbf{K g})\end{array}$ & Share (\%) \\
\hline Petani & 20.000 & 100,00 \\
Harga Jual & & \\
Biaya Pemasaran: & 125 & 0,62 \\
$\quad$ 1. Pengangkutan & 200 & 1 \\
$\quad$ 2. Pengemasan & 250 & 2,87 \\
$\quad$ 3. Retribusi & $\mathbf{5 7 5}$ & $\mathbf{2 , 8 7}$ \\
\hline Total Biaya & 20.000 & \\
\hline Harga Beli Konsumen Akhir & & $\mathbf{1 0 0 , 0 0}$ \\
\hline Farmer's Share (\%)
\end{tabular}

Sumber: Data Primer yang Diolah, 2019.

Tabel 8 menunjukkan bagian yang di terima petani adalah $100 \%$. Rata-rata biaya pemasaran pada saluran pemasaran I yaitu $\mathrm{Rp}$. 575 atau 2,87 persen dengan perincian biaya antara lain pengangkutan menggunakan angkutan umum (mobil), pengemasan dan retribusi. Saluran pemasaran ini petani menjual buah salak langsung ke konsumen akhir di pasar buhias dan di pelabuhan kapal laut tagulandang. Disini petani juga bersifat sebagai pedagang. Terdapat 2 responden petani yang menjual buah salak pada saluran pemasara I.

\section{Margin Pemasaran dan Farmer's Share Pada Saluran Pemasaran II}

Rata-rata biaya, keuntungan, margin pemasaran dan farmer's share pada saluran pemasaran II dapat dilihat pada Tabel 9.

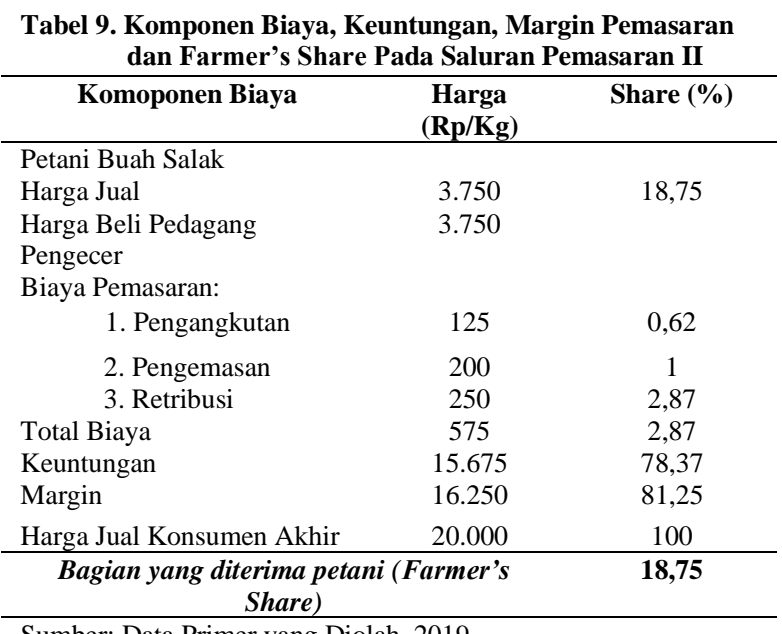

\section{Margin Pemasaran dan Farmer's Share Pada Saluran Pemasaran III}

Rata-rata biaya, keuntungan, margin pemasaran dan farmer's share pada saluran pemasaran III dapat dilihat pada Tabel 10.
Tabel 10. Komponen Biaya, Keuntungan, Margin Pemasaran dan Share Buah Salak Pada Saluran III dari Pusat Produksi Desa Bawoleu Ke Pedagang Besar di Manado

\begin{tabular}{lcc}
\multicolumn{1}{c}{ Komoponen Biaya } & $\begin{array}{c}\text { Harga } \\
\text { (Rp/Kg) }\end{array}$ & Share (\%) \\
\hline Petani Buah Salak & & \\
Harga Jual & 3.750 & 75 \\
Harga Beli Pedagang & 3.750 & 75 \\
Pengecer & & \\
Biaya Pemasaran: & & \\
$\quad$ 1. Pengangkutan & 125 & 2,5 \\
$\quad$ 2. Pengepakan & 125 & 2,5 \\
$\quad$ 3. Bongkar Muat & 625 & 12,5 \\
Total Biaya & 875 & 17,5 \\
Keuntungan & 375 & 7,5 \\
Margin & 1.250 & 25 \\
Harga Jual Pedagang & 5.000 & 100 \\
Pengumpul Ke Pedagang & & \\
besar di Manado & & $\mathbf{7 5}$ \\
\hline Farmer's Share & & \\
\hline Sumber: Data Primer yang Diolah, 2019.
\end{tabular}

Tabel 10 menunjukkan bahwa pada tingkat pedagang pengumpul harga beli buah salak dari petani yaitu sebesar Rp $3.750 / \mathrm{Kg}$ dan harga jual ke pedagang besar di manado yaitu sebesar Rp $5.000 / \mathrm{Kg}$. Pedagang pengumpul mengeluarkan biaya Rp 875 atau 17,5 persen, di sebabkan oleh jarak yang cukup jauh sehinggah pengangkutan dilakukan 2 kali dengan biaya transportasi yang besar menggunakan mobil pick up dari Desa Bawoleu ke pelabuhan kapal laut Tagulandang dan menggunakan kapal laut menuju ke pedagang besar di manado. Keuntungan pemasaran yang diperoleh pada saluran pemasaran III yaitu sebesar Rp 375 atau 7,5 Persen.

Total margin pemasaran pada saluran III yaitu sebesar $\mathrm{Rp} 1.250$ atau 25 persen sedangkan bagian yang diterima petani (farmer's share) pada saluran III yaitu sebesar 75 persen.

\section{KESIMPULAN DAN SARAN}

\section{Kesimpulan}

Berdasarkan hasil penelitian pemasaran buah salak di Desa Bawoleu Kecamatan Tagulandang Utara Kabupaten Sitaro dapat disimpulkan sebagai berikut:

1. Saluran pemasaran yang terbentuk pada pemasaran buah salak di Desa Bawoleu Kecamatan Tagulandang Utara Kabupaten Sitaro diperoleh ada 3 bentuk saluaran pemasaran. 
2. Saluran pemasaran I total biaya Rp. $575 / \mathrm{Kg}$, Saluran pemasaran II total biaya Rp $575 / \mathrm{kg}$, keuntungan $\mathrm{Rp} 15.675 / \mathrm{Kg}$ dan margin pemasaran Rp 16.250/Kg. Saluran pemasaran III total biaya $\mathrm{Rp} 875 / \mathrm{Kg}$, Keuntungan $\mathrm{Rp} 375 / \mathrm{Kg}$, margin pemasaran $\mathrm{Rp} 1.250 / \mathrm{Kg}$

3. Bagian yang diterima petani (farmer's share) pada saluran pemasaran I sebesar 100 $\%$, saluran pemasaran II sebesar $18,75 \%$, saluran pemasaran III sebesar $75 \%$.

\section{Saran}

Berdasarkan hasil penelitian dari ke dua saluran pemasaran buah salak di Desa Bawoleu disarankan:

1. Para petani lebih meningkatkan pemasaran buah salak karena peluang pemasaran buah salak baik di dalam maupun diluar daerah memiliki prospek yang sangat baik untuk terus dikembangkan.

2. Lembaga-lembaga pemasaran yang ada agar lebih meningkatkan kerjasama dalam kegiatan usahatani dan pemasaran buah salak sehingga baik petani maupun lembaga pemasaran yang ada dapat menerima harga yang layak.

\section{DAFTAR PUSTAKA}

Daniel. M, 2002. Pengantar Ekonomi Pertanian. Bumi Aksara, Jakarta.

Mosher, 1981. Menggerakkan dan Membangun Pertanian. Yasaguna, Jakarta. Diakses Tanggal 25 Oktober 2018.

Pearce dan Robinson, 2011. Manajemen Strategis: Formulasi, Implementasi dan Pengendalian. Penerbit Salemba Empat, Jakarta.

Rahim dan Diah Retno Dwi Hastuti, 2007. Ekonomi Pertanian, Pengantar Teori dan Kasus, Penebar Swadaya. Jakarta.

Soekartawi, 2005. Agribisnis: Teori dan Aplikasinya. PT. Raja Grafindo Persada. Jakarta.

Sudiyono A, 2004. Pemasaran Pertanian. Universitas Muhammadiyah Malang Press, Malang.

Sumodiningrat, G, 2000. Pengembangan Ekonomi Melalui Pengembangan Pertanian. Bina Rena Perwira, Jakarta. 